\title{
Childhood abuse is associated with methylation of multiple loci in adult DNA
}

\author{
Matthew Suderman ${ }^{1,2,3+}$, Nada Borghol ${ }^{1,2+}$, Jane J Pappas ${ }^{1,2+}$, Snehal M Pinto Pereira ${ }^{4}$, Marcus Pembrey ${ }^{5}$, \\ Clyde Hertzman ${ }^{6 \wedge}$, Chris Power ${ }^{4}$ and Moshe Szyf ${ }^{1,2^{*}}$
}

\begin{abstract}
Background: Childhood abuse is associated with increased adult disease risk, suggesting that processes acting over the long-term, such as epigenetic regulation of gene activity, may be involved. DNA methylation is a critical mechanism in epigenetic regulation. We aimed to establish whether childhood abuse was associated with adult DNA methylation profiles.

Methods: In 40 males from the 1958 British Birth Cohort we compared genome-wide promoter DNA methylation in blood taken at $45 \mathrm{y}$ for those with, versus those without, childhood abuse ( $n=12 \mathrm{vs} 28$ ). We analysed the promoter methylation of over 20,000 genes and 489 microRNAs, using MeDIP (methylated DNA immunoprecipitation) in triplicate.

Results: We found 997 differentially methylated gene promoters (311 hypermethylated and 686 hypomethylated) in association with childhood abuse and these promoters were enriched for genes involved in key cell signaling pathways related to transcriptional regulation and development. Using bisulfite-pyrosequencing, abuse-associated methylation (MeDIP) at the metalloproteinase gene, PM20D1, was validated and then replicated in an additional 27 males.

Abuse-associated methylation was observed in 39 microRNAs; in 6 of these, the hypermethylated state was consistent with the hypomethylation of their downstream gene targets. Although distributed across the genome, the differentially methylated promoters associated with child abuse clustered in genome regions of at least one megabase. The observations for child abuse showed little overlap with methylation patterns associated with socioeconomic position.

Conclusions: Our observed genome-wide methylation profiles in adult DNA associated with childhood abuse justify the further exploration of epigenetic regulation as a mediating mechanism for long-term health outcomes.
\end{abstract}

Keywords: Epigenetics, Childhood abuse, Early life environment, Epigenome, DNA methylation, Biomarker

\section{Background}

Abuse in childhood, encompassing physical, sexual or emotional abuse, is a key component of a broader spectrum of child maltreatment [1]. Life-long consequences of child abuse have been identified, including a greater risk of violence and delinquency, as well as adult depression and attempted suicide [1]. Hazardous behaviors, such as smoking and alcoholism, have also been found to be associated with abuse in childhood [2-4]

\footnotetext{
* Correspondence: moshe.szyf@mcgill.ca

${ }^{\dagger}$ Equal contributors

Deceased

'Sackler Program for Epigenetics \& Developmental Psychobiology, McGill University, 3655 Promenade Sir William Osler, Montreal H3G 1Y6 QC, Canada ${ }^{2}$ Department of Pharmacology and Therapeutics, McGill University, 3655 Promenade Sir William Osler, Montreal H3G 1Y6 QC, Canada Full list of author information is available at the end of the article
}

along with later disease risk factors, including obesity $[1,5]$, poorer immune function [1,6-8] earlier menarche [9-11] and outcomes such as ischemic heart disease $[6,12,13]$ and chronic obstructive lung disease $[13,14]$. Explanations including biological mechanisms for longterm outcomes of child abuse have yet to be fully explored.

DNA methylation and histone modification play crucial roles in development, adaptation and response to environmental signals [15]. Methylation of cytosine bases occurs at CpG sites and, in gene promoters, usually results in gene silencing, whereas loss of methylation is associated with activity. MicroRNAs that repress the expression of their often numerous target genes are also part of epigenetic regulation [16]. MicroRNAs can down regulate key players in the epigenetic regulation machinery,

\section{Biomed Central}


but can also be silenced themselves by DNA methylation [17]. Whilst epigenetic regulation, by definition, does not alter DNA sequence, DNA variants can influence methylation levels. However, DNA methylation associated with early adversity (prenatal famine) was found to be independent of that associated with genetic variation [18]. Evidence to date suggests that stable changes in DNA methylation in the hippocampus of humans [19] and rats [20,21] are triggered by maltreatment in early life.

Much DNA methylation is tissue specific [22] but most tissues are unavailable for population studies of living individuals. Given the multiple outcomes for childhood abuse, we hypothesize that DNA methylation associated with childhood abuse is system-wide [23]. Several recent studies have supported the possibility of differential DNA methylation associations with social adversity in peripheral blood cells. For example, Borghol et al., demonstrated association of DNA methylation profiles with early life socioeconomic position in blood cells [24]. Provencal et al., showed that differential maternal rearing is associated with differential DNA methylation profiles in both prefrontal cortex and blood T cells [25]. Klengel et al., demonstrated childhood trauma-dependent DNA demethylation in functional glucocorticoid response elements of FKBP5 in blood cells [26]. Mehta et al., have delineated recently DNA methylation signatures of child trauma and posttraumatic stress disorder in blood cells [27]. Although blood cells turn over, they are derived from stem cells and progenitors that stay with us for a life long. Thus, it is plausible that a DNA methylation event in a stem cell population that is introduced in early life remains into adulthood.

We therefore aimed to establish whether childhood abuse is associated with adult gene promoter methylation in a genome-wide investigation of peripheral blood cells [24]. We studied 40 adult males enrolled in the 1958 British Birth Cohort who have been found to have substantial variation in promoter methylation in over 6,000 genes, with a distinct methylation profile associated with socio-economic position [24]. Those with childhood abuse in this cohort have been shown to have long-term associations with negative health outcomes, specifically, a greater prevalence of obesity among those who reported physical abuse in childhood [28].

\section{Methods}

\section{Ethics statement}

All participants provided written consent and a blood sample for DNA analysis; ethical approval for a $45 \mathrm{y}$ biomedical survey and data analysis was given by the South-East Multi-Centre Research Ethics Committee (ref. 01/1/44) and the Joint UCL/UCLH Committees on the Ethnics of Human Research (Committee A) (ref. 08/H0714/40).

\section{Study population}

The selection of 40 adult males from the 1958 cohort [29] has been described previously [24] and are detailed in the Additional files. In brief, 17,638 participants were enrolled, all born in England, Scotland and Wales, during a single week in March 1958. At 45y, 4,177 males provided written consent and a blood sample for DNA analysis; ethical approval was given by the South-East Multi-Centre Research Ethics Committee. After exclusions (e.g. cancer or elevated C-reactive protein levels, immigrants), 3,362 white males were classified by socioeconomic position (SEP) and childhood abuse. Forty males were selected from extremes of SEP, including 12 who reported abuse (7 low and 5 high child SEP; 7 low and 5 high adult SEP). With exclusion of immigrants, the 1958 cohort shows little genetic population stratification [30].

Abuse was identified through participants' reports in a confidential questionnaire at $45 \mathrm{y}$ on the following experiences to age 16y: [1] "I was verbally abused by a parent"; [2] "I suffered humiliation, ridicule, bullying or mental cruelty from a parent"; [3] "I was physically abused by a parent punched, kicked or hit or beaten with an object, or needed medical treatment"; [4] "I was sexually abused by a parent". A report of any of these was scored as abuse. These questions were from the PATH Through Life Project including items derived from the Parental Bonding Instrument, the British National Survey of Health and Development and the US National Comorbidity Survey [31].

\section{Measurement of relative DNA methylation levels}

DNA sample preparation, methylated DNA immunoprecipitation (MeDIP) and microarray hybridization, scanning and data extraction were performed as described previously [24]. Briefly, DNA was extracted from whole blood collected in EDTA at 45 years using an in-house, manual guanidine hydrochloride and ethanol precipitation method. DNA promoter methylation data from 20,533 genes and 489 microRNAs for the 40 participants were generated using MeDIP with an antibody that recognizes and binds 5-methylcytosine (DNA methylation) to isolate methylated DNA fragments. These fragments were then hybridized to custom-designed, high-density oligonucleotide microarrays, covering approximately $1000 \mathrm{bp}$ upstream to $250 \mathrm{bp}$ downstream at $100 \mathrm{bp}$ spacing from the transcription start sites (TSS) in Ensembl (version 44). Microarray data files used in this study can be downloaded from the Gene Expression Omnibus (accession number: GSE31713). Three replicate microarrays were generated per individual and demonstrated adequate reproducibility [24]. Both hierarchical clustering and principal components analysis applied to the 500 most variable probes across all microarrays showed that the three replicates clustered. Furthermore, $>70 \%$ of the variance in these probes was explained by individual variation. 


\section{Microarray statistical analysis}

The steps taken in the microarray statistical analysis are shown in Additional file 1: Figure S1 and justification for our approach is given in Additional files. Quality control involved generating MvA plots (i.e. plots of $\log (\mathrm{Cy} 5 / \mathrm{Cy} 3)$ vs $\log (\mathrm{Cy} 5 \times \mathrm{Cy} 3))$ to identify those with severe dye biases or low signal. Microarrays deemed unacceptable were repeated, so no sample was excluded by quality control. Unsupervised clustering failed to identify batch effects related to hybridization date. Normalization of the final set of microarrays proceeded by computing log ratios of the bound (Cy5) and input (Cy3) microarray channel intensities for each microarray and then microarrays were normalized to one another using quantile normalization under the assumption that all samples have identical overall methylation levels. A probe was called differentially methylated if the modified t-statistic from 'limma' [32] of Bioconductor [33] was significant $(\mathrm{p}<0.05)$ and the $\log 2$ fold-difference of the mean group probe intensities was $\geq 0.25$. A promoter was called differentially methylated if it contained a probe called differentially methylated and if it contained probes for which modified t-statistics were significantly higher or lower than the average probe on the microarray. Significance for the latter was determined by applying the Wilcoxon rank-sum test and then calculating a corresponding false discovery rate (FDR) [34] using the method of Benjamini and Hochberg [35]. Promoters with FDR < $20 \%$ were called differentially methylated. This false discovery rate (FDR) was designed to test the chances of an overall false discovery among a series of related results. It is particularly useful for an exploratory analysis concerned with making general inferences from among a set of 'discoveries', rather than guarding against one or more individual false positives. The FDR threshold of $20 \%$ used here indicates that the expected proportion of promoters incorrectly called differentially methylated is around $20 \%$. We find this threshold acceptable because this preliminary study is not meant to definitively characterise the epigenetic signatures of childhood abuse. In Figure 1, we present a heatmap showing probe methylation scores averaged across triplicate microarrays. Clustering was performed using Ward's hierarchical clustering algorithm with Pearson correlation distance as the distance metric.

All bioinformatic functional analysis was based on gene sets from GO [36], KEGG [37] and mSigDB [38]. Enrichment for differential methylation was determined by applying the hypergeometric test to the overlap between known gene sets and those found in our study to be differentially methylated. FDR values were obtained by adjusting these significance levels over all gene sets and pathways considered. The differentially methylated gene set was then subjected to pathway analysis using Ingenuity Pathway Analysis software (http://ingenuity. com/products/pathways_analysis.html).

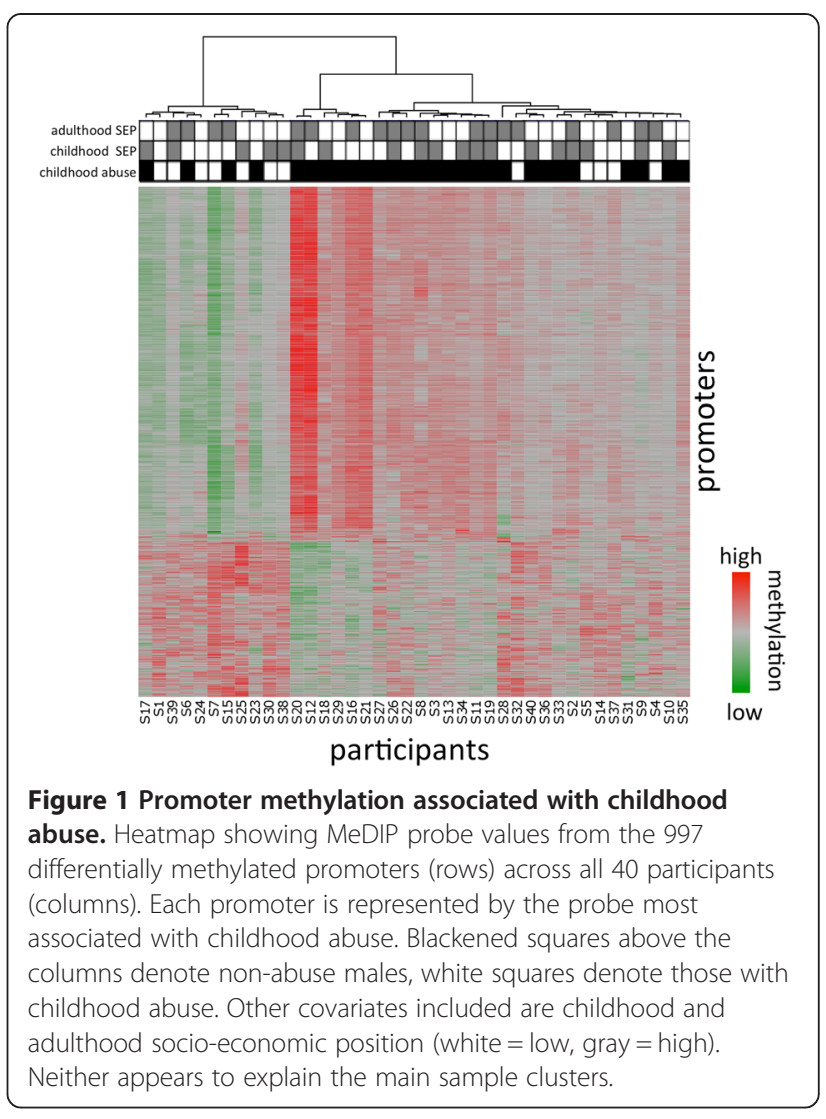

In assessing megabase regions of the genome, methylation patterns were obtained by computing the mean methylation score difference between abuse and non-abuse groups for each probe, generating a UCSC wiggle track file from these differences and then uploading it for display on the UCSC genome browser (http://genome.ucsc.edu/).

\section{Validation and further methylation analysis}

First, we validated the microarray calls, selecting 11 genes with the strongest methylation association with abuse (Additional file 2: Figure S2). Validation was performed using quantitative PCR (qPCR) of bound and input fractions of MeDIP with primers flanking the differentially methylated regions (Additional file 3: Table S1). Second, we validated two of these 11 genes, SLC17A3 and PM20D1, hypermethylated in association with abuse on MeDIP, by bisulfite pyrosequencing (in participants with sufficient DNA), as an independent method that measures methylation at specific sites [39]. Next, bisulfite pyrosequencing analysis of PM20D1 was repeated on an additional 27 males selected using the same criteria as the original [40] group. Details of pyrosequencing conditions, including optimization of PCR amplification using 0, 50 and 100\% methylation controls are provided in Additional files.

Cell type ratios in blood are known to fluctuate so certain methylation differences between individuals could 
be caused by different cell ratios, particularly in promoters of genes with cell-type specific methylation. To rule out this possibility in our analysis, we compared our results to published MeDIP [40], expression [41] and Illumina $450 \mathrm{~K}$ [42] profiles of purified blood cell types. In each published dataset, we identified all differentially methylated or expressed genes or probes (as appropriate) between all pairs of available blood cell type profiles and then compared those lists of differences to the list of differentially methylated genes or probes between the abused and non-abused individuals in our study. If variation in blood cell type ratios explains the methylation differences in our analysis, then we would expect to see at least one larger-than-expected intersection. In each case, however, hypergeometric tests failed to identify larger-than-expected intersections ( $p>0.4$ in each case). For the published MeDIP dataset [40], the microarray design used was similar to our design so we were able to construct a 1-1 mapping between over half of the probes across our respective designs. Probes were paired if they were closest and within $150 \mathrm{bp}$. Unfortunately, this MeDIP dataset only contained profiles for $\mathrm{B}$ and $\mathrm{T}$ cell purified cell types. We therefore expanded our analysis to include an expression dataset [41] with profiles for CD33+ (myeloid), CD34+, CD71+ (early erythroid), CD4+, CD8+, CD14+ (monocyte), CD19+ (B) and CD56 (natural killer) cells. We also included a recent Illumina $450 \mathrm{~K}$ dataset [42] with profiles for granulocytes, neutrophils, eosinophils, CD4+, CD8+, CD14+, CD19+ and CD56+ cells. For both these datasets, results were compared at the gene level.

\section{Results and discussion}

Physical, cognitive and emotional characteristics and biomarkers are listed for participants in Table 1. As expected, the abuse group showed more adverse characteristics than the non-abuse group, but differences did not reach conventional $\mathrm{p}$-values in this small sample.

\section{Hundreds of promoters are differentially methylated in association with child abuse}

In total, 997 gene promoters were differentially methylated in association with childhood abuse, affecting 1141 different genes (Additional files). Of these promoters, 311 were hypermethylated and 686 were hypomethylated in abused compared to non-abused males. Figure 1 shows a heatmap depicting the relative methylation levels for all differentially methylated promoters and how they cluster within study participants. Even at more stringent thresholds $(\mathrm{p}<$ 0.01 and $\mathrm{q}<0.05$, see Methods), there were still 34 differentially methylated promoters corresponding to 58 different genes with similar proportions hypermethylated to hypomethylated. These cluster the study participants very similarly to the larger set of differentially methylated promoters (Additional file 4: Figure S3). To assess whether the broad methylation signature of childhood abuse was affected by the numerical imbalance of abused versus nonabused ( $\mathrm{N}=12$ vs 28), we conducted a permutation analysis. We found that 997 differentially methylated promoters between abused and non-abused was larger than the number of differences associated with $82 \%$ of random partitions (410 of 500) of the participants with partition size ratios corresponding to 12 vs 28 . To address any concern that the abuse associated methylation differences were reflecting differences in blood cell type ratios, we compared our results with recently published expression and methylation profiles of purified cell types [40-42]. We found no evidence of statistically significant overlaps between our results for abuse and cell-type specific methylation and expression patterns $(\mathrm{p}>0.4$, hypergeometric test; see Methods for details).

In 11 genes selected for validation, the direction of abuse associated methylation differences was confirmed using qPCR of bound and input MeDIP fractions (Additional file 2: Figure S2). We also confirmed abuse associated hypermethylation by pyrosequencing of sites in the promoter of $S L C 17 A 3$ and the first exon of PM20D1 in the original samples (Figure 2A) and in an additional 27 males for PM2OD1 (Figure 2B), and with SNP rs11540014 showing no association with methylation levels (data not shown). However, the associations in the promoter of SLC17A3 were not replicated in the additional 27 males.

\section{Abuse-associated methylation clusters by biological function}

Full results of functional analysis are given in Additional files. Differentially methylated gene promoters in abused males (1141 genes) were enriched in regulatory (169 genes) and developmental (230 genes) functions (Table 2). Central to both of these functions is the KEGG WNT signaling pathway; enriched for genes [15] for which promoters are hypomethylated in abused individuals, consistent with activation of this pathway in blood cells of the abuse group (Figure 3). No other KEGG pathway was enriched with differentially methylated genes at $\mathrm{p}<0.05$ (uncorrected for multiple testing). Of the differentially methylated genes that perform some regulatory function, most (134 of 169) are hypomethylated in abused males. The regulation mainly affects transcription as indicated by enrichment of these genes in functional categories such as chromatin modification (28 genes), histone modification (11 genes) and transcription factor binding (35 genes). Similarly, most of the 230 developmental genes are hypomethylated in abused males (172 genes), best characterized by the general gene ontology category "multicellular organismal development" (163 genes). More specific subcategories do not show significant enrichment. 
Table 1 Characteristics of the $\mathbf{4 0}$ male study participants

\begin{tabular}{|c|c|c|c|c|}
\hline & Age (y) & No abuse $n=28$ & Abuse $n=12$ & $p^{*}$ \\
\hline Birthweight, g, mean $\pm \mathrm{SD}^{\#}$ & 0 & $3577.35(574.91)$ & $3338.21(590.25)$ & 0.24 \\
\hline Height, $\mathrm{cm}$, mean $\pm S D^{\# \$}$ & 7 & $1.24(0.07)$ & $1.21(0.07)$ & 0.27 \\
\hline Maths score, mean $\pm S D^{\# \$}$ & 16 & $14.82(7.32)$ & $12.29(7.95)$ & 0.44 \\
\hline Reading score, median (Q1, Q3) & 16 & $27(21,31)$ & $31(12,32)$ & 0.70 \\
\hline Socio-emotional adjustment number $\sim$ median $(\mathrm{Q} 1-\mathrm{Q} 3)^{\# \$}$ & 7 & $4(1,12)$ & $8.5(2,13)$ & 0.47 \\
\hline Alcohol drinks daily, $n(\%)^{\#}$ & 42 & $7(25.93)$ & $2(16.67)$ & 0.53 \\
\hline Smokers, n (\%) ${ }^{\#}$ & 42 & $7(25.93)$ & $4(33.33)$ & 0.64 \\
\hline Height, $\mathrm{cm}$, mean $\pm \mathrm{SD}^{\#}$ & 42 & $1.78(0.09)$ & $1.76(0.06)$ & 0.52 \\
\hline $\mathrm{BMl}, \mathrm{kg} / \mathrm{m}^{2}$, mean $\pm \mathrm{SD}$ & 45 & $26.63(3.99)$ & $28.69(4.39)$ & 0.16 \\
\hline Waist circumference, $\mathrm{cm}$, mean $\pm \mathrm{SD}$ & 45 & $97.43(10.24)$ & $102(12.02)$ & 0.23 \\
\hline Diastolic blood pressure, $\mathrm{mmHg}$, mean $\pm \mathrm{SD}$ & 45 & $82.77(11.71)$ & $85.53(12.72)$ & 0.51 \\
\hline Systolic blood pressure, $\mathrm{mmHg}$, mean $\pm \mathrm{SD}$ & 45 & $132.92(18.61)$ & $134.72(18.90)$ & 0.78 \\
\hline $\mathrm{Fev} 1^{\dagger}$, mean $\pm \mathrm{SD} \#$ & 45 & $3.84(0.65)$ & $3.70(0.63)$ & 0.53 \\
\hline
\end{tabular}

${ }^{\dagger} \mathrm{FEV} 1$ = one-second forced expiratory volume; best test of three spirometry readings.

${ }^{\#} \mathrm{~N}$ for non-abuse $<28$ (range 22 to 27 ).

${ }^{\$} \mathrm{~N}$ for abuse $<12$ (range 7 to 10 ).

$\sim$ higher score $=$ poorer adjustment.

*p-value from t-test, except for median (IQR), when Two-sample Wilcoxon rank-sum test was used.

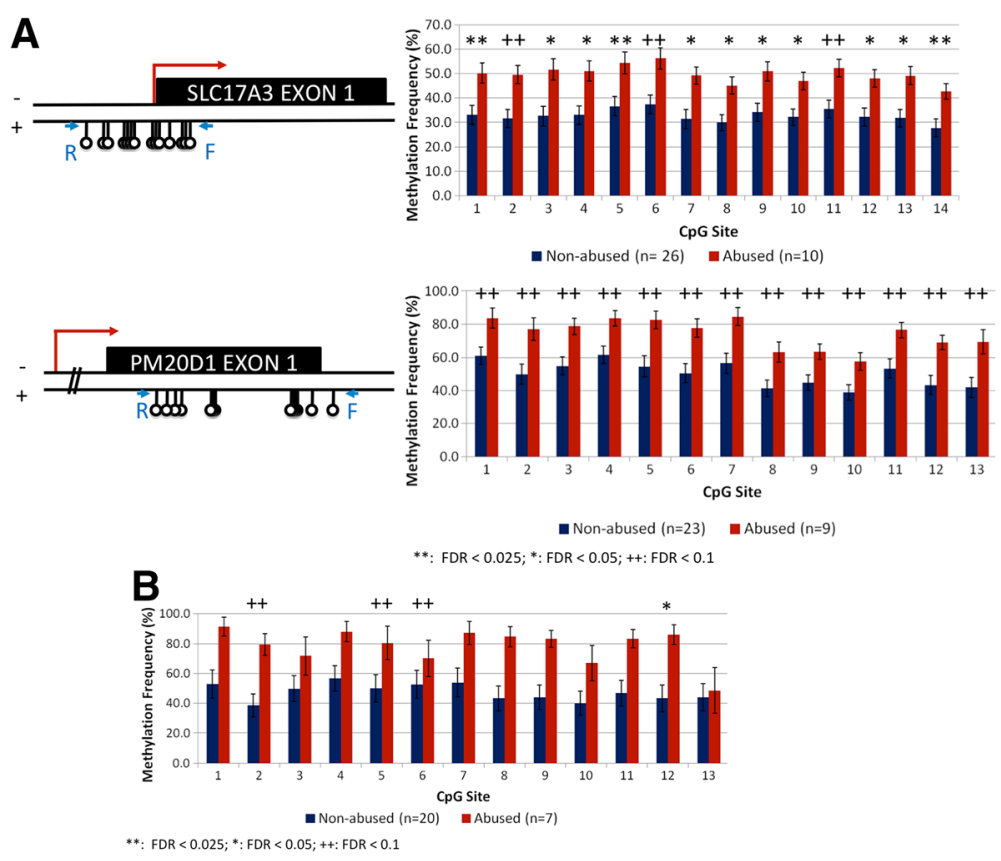

Figure 2 Validation of MeDIP results. A. Quantification of methylation differences in the abuse and non-abuse groups by bisulfite pyrosequencing analysis of the SLC17A3 promoter and the PM20D1 first exon and intron. DNA methylation at 14 CpG sites in the SLC17A3 promoter and 12 and 1 CpG sites in the PM20D1 first exon and first intron, respectively, among the abuse and non-abuse groups is shown ( $N=10$ vs. 26 for $S L C 17 A 3 ; N=9$ vs 23 for PM20D1). One-sided t-tests were applied to each CpG site to test for association of methylation levels with childhood abuse, and false discovery rates were calculated for the resulting $\mathrm{p}$-values in order to correct for multiple testing. All false discovery rates (FDR) were less than 0.1 , indicating significant association between CpG methylation levels and childhood abuse. **: FDR $<0.025$; *: FDR $<0.05$; ++: FDR $<0.1$; +: FDR $<0.2$. The bars represent average methylation for all subjects in a group and error bars indicate the standard error of the mean. Physical maps of the regions analyzed are presented above the charts where CpG positions are indicated by balloons. The transcription start site (TSS) is indicated by a hook arrow. The positions of the primers used for pyrosequencing (Additional file 3: Table S2) are indicated by arrows. B. Replication of the quantification of the differences in methylation at PM20D1 between the abuse and non-abuse groups in an additional 27 males that were not profiled using MeDIP ( $N=7$ vs. 20). Pyrosequencing was applied to measure the methylation levels of 13 CpG sites in the first exon and intron of PM20D1. 
Table 2 Selected functional analysis of abuse associated hypo- and hypermethylation

\begin{tabular}{|c|c|c|c|c|c|c|c|c|c|}
\hline \multirow[t]{2}{*}{ Pathway/function } & \multirow{2}{*}{$\begin{array}{l}\text { Number of genes } \\
\text { in pathway/function }\end{array}$} & \multicolumn{2}{|c|}{ Differentially methylated } & \multicolumn{3}{|c|}{ Hypo-methylated } & \multicolumn{3}{|c|}{ Hyper-methylated } \\
\hline & & $\mathbf{n}$ & $p$ & $\mathbf{n}$ & $p$ & $\mathrm{fdr}$ & $\mathrm{n}$ & $p$ & fdr \\
\hline WNT signaling pathway & 142 & 19 & 0.0013 & 15 & 0.0020 & 0.53 & 4 & 0.22 & 1 \\
\hline Regulation & 2330 & 169 & 0.017 & 134 & 0.0018 & 0.51 & 33 & 0.88 & 1 \\
\hline - Chromatin modification & 273 & 32 & 0.0004 & 28 & 0.00005 & 0.09 & 4 & 0.68 & 1 \\
\hline - Histone modification & 105 & 13 & 0.013 & 11 & 0.008 & 0.94 & 2 & 0.53 & 1 \\
\hline - Transcription factor binding & 493 & 41 & 0.034 & 35 & 0.006 & 0.84 & 6 & 0.84 & 1 \\
\hline Development & 3054 & 230 & 0.0007 & 172 & 0.00096 & 0.40 & 58 & 0.17 & 1 \\
\hline - Multicellular organismal development & 2838 & 213 & 0.0012 & 163 & 0.0006 & 0.32 & 50 & 0.32 & 1 \\
\hline Cell surface receptor linked signal transduction & 1778 & 125 & 0.071 & 79 & 0.60 & 1 & 46 & 0.002 & 0.53 \\
\hline
\end{tabular}

' $n$ ' is the number of genes in the relevant pathway that are differentially methylated in association with abuse. ' $p$ ' was calculated using the hypergeometric test, it indicates the statistical significance of the enrichment. ' $f d r$ ' the false discovery rate (FDR) corresponding to the $p$-value.

Differentially hypermethylated gene promoters in abused males are enriched in few functional categories. One of these, "cell surface receptor linked signal transduction", contains 125 genes with differentially methylated promoters of which 46 are hypermethylated in abused individuals. An Ingenuity functional analysis of the differentially methylated genes revealed similar molecular and cellular functions associated with transcriptional control (Additional file 5: Figure S4).

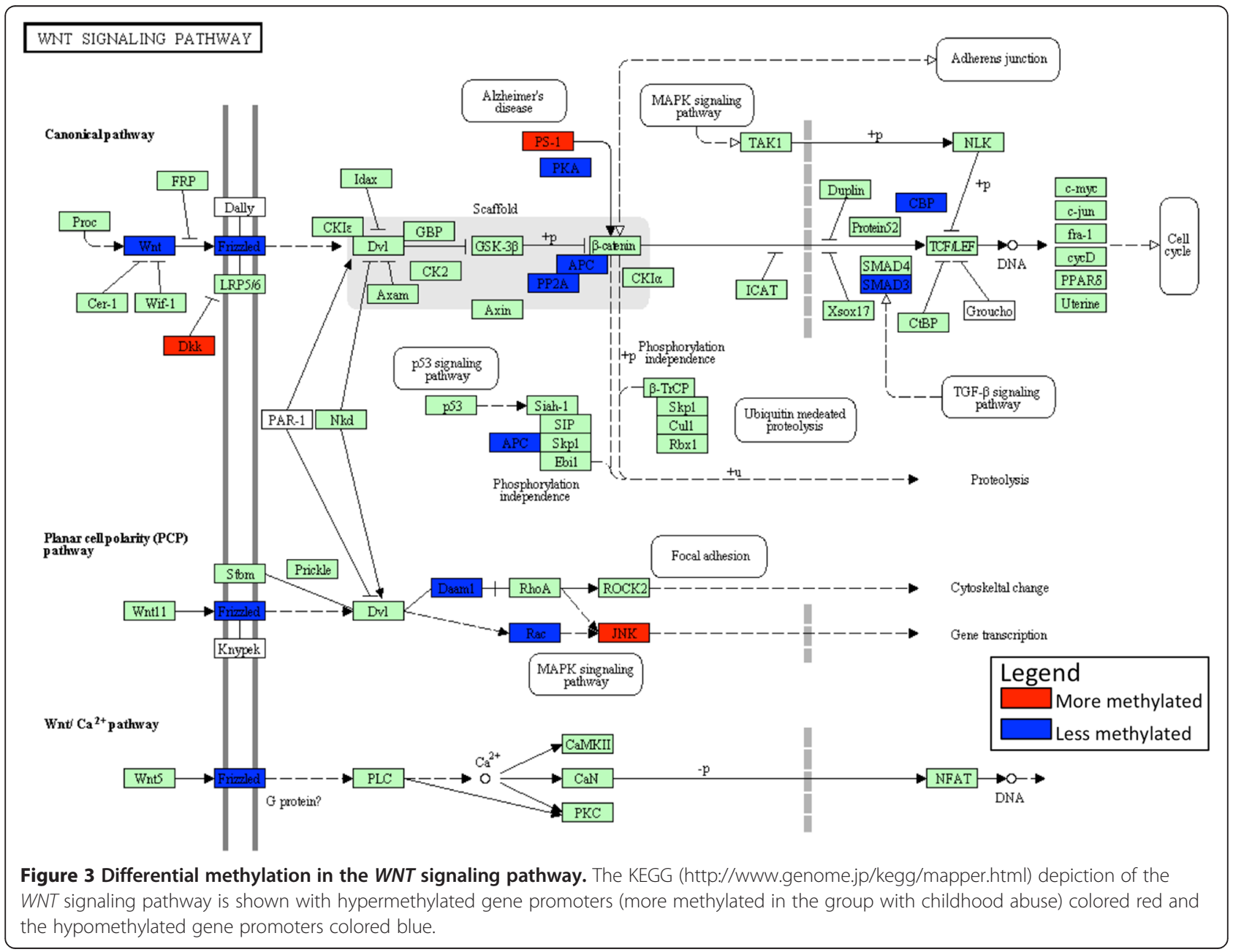




\section{Abuse-associated methylation consistent with microRNA targeting}

MicroRNA genes are, like DNA methylation, known to repress the expression of target genes. However, unlike an individual methylation mark which typically targets a single nearby gene, each microRNA is associated with a specific set of a few hundred target genes [43]. We discovered an association of microRNA DNA hypermethylation with abuse. Of 489 microRNAs analysed, 39 were differentially methylated, of which 31 were hypermethylated in association with abuse. The target genes of six of these included a highly non-random proportion of genes with decreased promoter methylation in abused males (Table 3).

\section{Abuse-associated hypomethylation and CpG density}

DNA methylation in regions of relatively high $\mathrm{CpG}$ frequency, known as CpG islands, plays an important regulatory role in the otherwise CpG-depleted $(\leq 40 \%$ of that expected) mammalian genome $[44,45]$. In spite of the fact that MeDIP is known to enrich for methylation differences away from CpG islands [46], we observed unusually high $\mathrm{CpG}$ frequencies in promoters with reduced methylation levels in abused individuals. This frequency
(0.86) is significantly higher than that observed in the average promoter (frequency $=0.42 ; \mathrm{p}<1.4 \times 10^{-285}$ ) as well as promoters with increased methylation levels in abused individuals (frequency $=0.38 ; \mathrm{p}<4 \times 10^{-138}$; Additional file 6: Figure S5). This frequency (0.86) is even higher than the 0.6 threshold used to define CpG islands.

\section{Abuse-associated methylation clusters by genomic location}

Differentially methylated DNA loci associated with early life environments tend to cluster in the genome [24,47]. Chromosome-wide views of our data reveal megabasesized regions significantly enriched for differentially methylated promoters (Figure 4). At the chromosomal level, chromosomes 16 and 17 were significantly enriched for hypomethylated promoters in abused individuals, whereas chromosome $\mathrm{X}$ was significantly enriched for hypermethylated promoters. At the megabase level, three regions were significantly enriched for differentially methylated promoters $(\mathrm{p}<0.05)$. All were hypermethylated in abused individuals: chr1:246250000-247000000, chr14:10 0250000-101000000 and chr19:58500000-59250000 (genome assembly hg18), but only the regions on chromosomes 1 and 19 passed multiple testing correction with

Table 3 Methylation of microRNAs and their target genes

\begin{tabular}{|c|c|c|c|c|c|c|}
\hline MicroRNA & $\begin{array}{l}\text { Number of } \\
\text { targets }\end{array}$ & $\begin{array}{c}\text { Number } \\
\text { hypo-methylated }\end{array}$ & $\begin{array}{c}\text { Number } \\
\text { hyper-methylated }\end{array}$ & Hypomethylated targets & $\begin{array}{l}\text { Enrichment } \\
\text { p-value }\end{array}$ & $\begin{array}{l}\text { MicroRNA } \\
\text { methylation }\end{array}$ \\
\hline mir-514 & 49 & 10 & 1 & $\begin{array}{l}\text { AFF4, BAALC, BRWD1, CARM1, ENAH, } \\
\text { KLF13, MYO1B, NR3C1, SVIL, TCF12 }\end{array}$ & 5.71E-05 & hypermethylated \\
\hline let-7d & 320 & 26 & 6 & $\begin{array}{c}\text { ATP2A2, BACH1, BRWD1, CDV3, CHD4, } \\
\text { CPSF4, DCUN1D2, DOCK3, DOT1L, EFHD2, } \\
\text { EZH2, GGA3, LIMD2, LRIG1, MECP2, MGAT4A, } \\
\text { MIB1, MLL5, PARD6B, PBX3, PRTG, PTPRU, } \\
\text { RDH10, SOCS1, UNC5A, WDR37 }\end{array}$ & 0.0030 & hypermethylated \\
\hline mir-520c & 274 & 23 & 3 & $\begin{array}{l}\text { ASF1B, BCL2L11, BRP44L, DDHD1, DPYSL5, FLT1, } \\
\text { FNDC3B, INHBB, KCNMA1, KLF13, MAP3K14, } \\
\text { MECP2, MKNK2, MTUS1, ORMDL3, PBX3, PFN2, } \\
\text { RGL1, SMAD2, UBE2Q2, WDR37, ZFP36L2, ZFPM2 }\end{array}$ & 0.0035 & hypermethylated \\
\hline mir-215 & 37 & 6 & 0 & $\begin{array}{c}\text { ARFGEF1, FNDC3B, GRHL1, KLHDC5, } \\
\text { LRRFIP1, MECP2 }\end{array}$ & 0.0060 & hypermethylated \\
\hline mir-519a & 377 & 28 & 4 & $\begin{array}{l}\text { AFF4, BRWD1, BTG3, CELSR2, DNAJB6, LRIG1, } \\
\text { MAP3K5, MAP4, MASTL, MCM7, MECP2, MIB1, } \\
\text { NPAS2, OBFC2A, PARD6B, PFN2, PTHLH, } \\
\text { RAPGEF4, RASD1, SCAMP2, SFRS2, SMOC2, } \\
\text { TMEM64, VGLL3, WHSC1, YES1, ZFPM2, ZFYV9 }\end{array}$ & 0.0074 & hypermethylated \\
\hline mir-519e & 104 & 11 & 2 & $\begin{array}{l}\text { ARHGEF12, ARL4C, BCOR, CCNG2, CTDSPL2, } \\
\text { DLL1, DPYSL5, EFNB3, NEDD4L, NPAS2, RAB35 }\end{array}$ & 0.0075 & hypermethylated \\
\hline mir-203 & 239 & 20 & 3 & $\begin{array}{c}\text { AFF4, BCL7A, CNTFR, CTDSPL2, DNMT3B, EGR1, } \\
\text { FALZ, INSIG1, KCTD9, LASP1, MECP2, PLD2, } \\
\text { PPM1B, RAPGEF4, SLC12A2, SMAD1, SPEN, } \\
\text { SPIRE1, TCF12, YWHAQ }\end{array}$ & 0.0064 & hypomethylated \\
\hline
\end{tabular}

MicroRNAs are listed that have statistically significant MeDIP differences between abuse and non-abuse groups whose predicted gene targets are enriched for gene promoters that are also differentially methylated between abuse and non-abuse groups. In each case, enrichment is for targets with lower methylation in the abused group.

"enrichment p-value" indicates the level of enrichment for hypomethylated targets.

"microRNA methylation" indicates whether the data predicts significantly higher ("hypermethylated") or lower ("hypomethylated") methylation levels in the abuse group. 


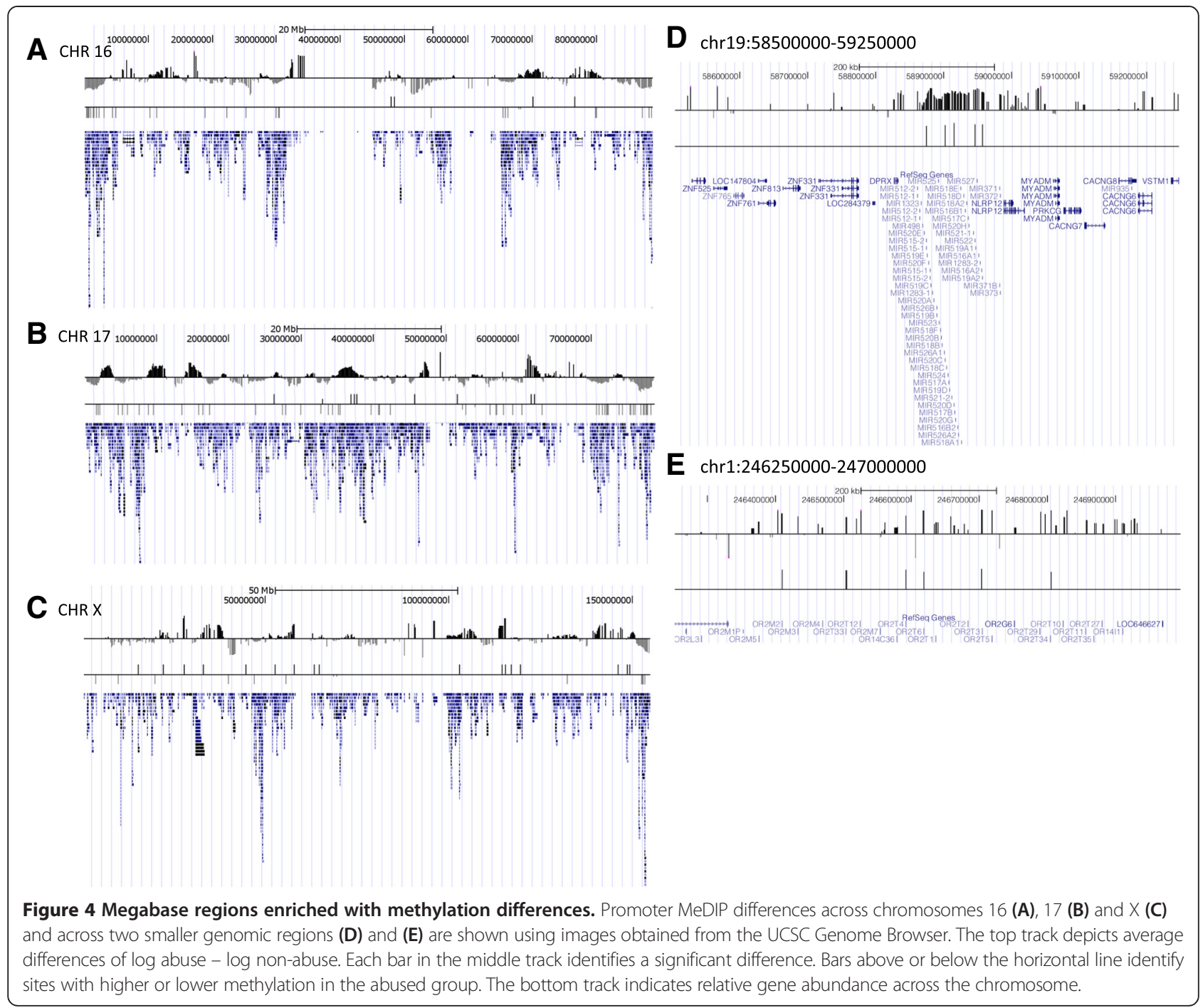

FDR below 0.2 (FDR $<0.006$ and 0.0001 , respectively; Figure 4D,E). The regions on chromosomes 14 and 19 each contain a cluster of microRNAs in which promoters account for all of their statistically significant site-specific differential methylation.

Clustering of differential promoter methylation, up to $2 \mathrm{Mb}$ apart, was detectable across the entire genome (Additional file 7: Figure S6).

\section{Socio-economic position (SEP) and abuse}

Previously, we identified 1252 gene promoters associated with childhood SEP and 545 associated with adulthood SEP [24]. Only 73 of 1252 (5.8\%) and 19 of 545 (3.5\%) gene promoters were also differentially methylated in association with childhood abuse. Just three (CTAGE5, GNG4, MYO1B) were differentially methylated in association with all three characteristics (childhood and adult SEP and childhood abuse). The association for PM20D1 was specific to abuse.

\section{Conclusions}

Blood DNA of 45y old males revealed differentially methylated gene promoters associated with abuse that occurred three decades earlier in childhood. There were several novel findings from our study. First, hundreds of specific promoter associations were uncovered, with approximately two-thirds hypomethylated in the abused group. Second, replication confirmed that hypermethylation in PM20D1 is associated with childhood abuse. Third, microRNA gene targets tended to be hypomethylated, particularly when the microRNA itself was hypermethylated. Fourth, differentially methylated genes were clustered in discrete functional pathways and in genomic locations. These findings support the hypothesis that the differences in DNA methylation we observed were non-random and reflect an organized biological process.

It is now known that genes act through functional and interacting pathways, so we adopted a genome-wide approach to DNA methylation analysis, recognizing that 
modest epigenetic changes in numerous genes could reset the function of gene networks having phenotypic effects. We found enrichment of differentially methylated promoters in the WNT signaling pathway complex with hypomethylation of 15 genes in the abused. Elsewhere this pathway complex has been found to play a key role in embryonic development and cellular proliferation [48], and is deregulated in some chronic health conditions such as obesity [49-51], diabetes [52-54], metabolic syndrome [55], cancer [56-59] and inflammatory processes [56-58]. Whilst recognizing that our findings do not provide evidence for causal links between child abuse and later outcomes, they nonetheless raise the prospect of mediation by epigenetic modifications.

Of particular note was hypermethylation of PM2OD1 in association with abuse, given a previous study showing a variably methylated region at this metalloproteinase gene was hypermethylated in association with obesity [60]. This association persisted over 10 years of follow-up in an elderly population. Interestingly, child abuse has been shown to be associated with adult obesity in the full 1958 cohort [5] and is suggested by our Table 1 . It is perhaps surprising to note that both our association with childhood abuse and the association with obesity were observed in blood DNA when PM20D1 has its highest expression levels in the brain and lowest expression levels in blood [41]. Given that it is highly conserved from yeast to human, it likely plays a key though little understood role in the cell. By contrast, SLC17A3 is like most of the genes differentially methylated in childhood abuse, most highly expressed in blood and a few specific brain regions (hypothalamus, prefrontal cortex, pituitary) [41]. It appears conserved in fewer species, mainly the higher mammals, and the expressed protein acts as a voltage-driven transporter in blood. Given this basic role, it is likely essential at nearly all stages of life.

Further support for epigenetic regulation working through interacting pathways comes from the striking enrichment in the abuse group of hypermethylated microRNAs combined with hypomethylation of their respective gene targets across the genome. It implies that during typical development, active transcription of these microRNAs is combined with synergistic target methylation to create a double layer of repression of these target genes; a repression that is lifted in association with child abuse.

Intriguingly, hypomethylated gene promoters in abused individuals typically contained sequences with very high CpG frequency. Demethylation of such CpG-rich promoters in abused males suggests that abuse leads to increased activity of key basic cellular functions, such as gene regulation and development, as found in pathway analysis. Another genomic feature associated with abuse was the clustering of differential promoter methylation detectable across the entire genome, providing further evidence of genome-wide as well as gene-specific organization of epigenetic profiles.

Previously we observed genome-wide clustering in association with SEP, but importantly, the "methylation signature" for abuse differed, such that $<10 \%$ of the differentially methylated regions overlapped with childhood SEP [24]. Also, the differentially methylated genes were enriched in different functional pathways, notably, MAP kinase for SEP and $W N T$ for child abuse. Further, the abuse associated differential methylation of microRNAs and their target genes was not seen for SEP. Whilst not ruling out generic associations with early life adversities, our findings suggest that different adversities are associated with different epigenetic changes to the genome.

Several methodological considerations arise here. First, reliable measurement of the frequency and severity of child abuse is not straightforward ${ }^{1}$. Child abuse was identified through participant's report at $45 \mathrm{y}$ and was primarily emotional and physical abuse - only rarely sexual abuse. All measures have biases and inconsistencies yet retrospective reports are an accepted method of ascertainment in population studies [1]. Furthermore, prospective identification of abuse is not feasible in large studies and likely to be unrepresentative. By contrast, retrospective selfreport, used here, is feasible though it is likely to underestimate true levels of abuse. Second, given the scale of assessing methylation at all promoters, we could only study a small but selected sample. Whilst our study is imbalanced with respect to abuse (12 vs 28 ) it has the benefit of control for SEP. Third, we used DNA from whole blood to test our hypothesis, currently the only practical option for population based studies. We cannot know the extent to which our results relate to gene expression. Use of whole blood also raises the possibility that abuse-associated differences in B-to-T cell ratios might account for some of our observations. We have partly addressed this by noting that B-cell and T-cell expression and methylation profiles $[40,41]$ do not differ for many genes with abuse-associated methylation levels. Fourth, those abused in childhood might represent a distinct genetic group, but genetic differences alone are unlikely to account for all methylation differences observed here. Given the possibility of differences in epigenetic response due to genetic variation, future integrated studies of the epigenome and whole genome sequencing are an important next step. Fifth, our study is imbalanced including 28 controls compared to only 12 with childhood abuse resulting in reduced power to identify methylation differences. Nonetheless, this preliminary study was able to discover hundreds of differentially methylated promoters so future studies with better balance are likely discover many more. Finally, there is currently no 'gold standard' for measuring the methylome, yet MeDIP is a well-established genome-wide method that has been evaluated [46,61-65] and we confirmed all the micro-array calls in the top 11 
methylation differences. Current genome-wide methods are more complementary than interchangeable and each has its strengths and weaknesses. Our analyses included triplicate arrays and methylation differences were confirmed in selected genes using other gene-specific methods both here and previously [24]. In using an analytic approach that was sensitive to subtle methylation associations across gene networks necessarily results in some false positives (for justification see Additional files). However, the non-random organization of methylation differences throughout the genome supports our main hypothesis that childhood abuse is associated with DNA methylation changes in adult blood.

In sum, the pattern of changes associated with child abuse detected in peripheral blood cells of 45 year-olds suggest that there is a system-wide readjustment of the epigenome to signals triggered by early life abuse. Our study does not demonstrate causality, nor can it demonstrate a temporal relationship between child abuse and DNA methylation levels in adulthood. It does, however, provide a justification for a range of studies addressing epigenetic responses to child abuse and their mediating role with later phenotypic outcomes.

\section{Additional files}

Additional file 1: Figure S1. Summary of methods.

Additional file 2: Figure S2. Validation by $q P C R$. Eleven gene promoters identified by microarray as being differentially methylated were subjected to real-time PCR quantification of the enrichment by the MeDIP procedure. Results were normalized against a methylated luciferase gene-containing plasmid (control), which was added to every sample in equal quantity before MeDIP. The $y$-axis represents relative concentration levels generated by applying PCR to methylation-enriched DNA. Each real-time PCR reaction was performed in duplicate for all subjects. Shown are the averages per group. Error bars indicate the standard error of the mean. Above the chart are tracks of the regions with the microarray data. (The bars indicate the difference between the abuse and the non-abuse groups, bars descending from the physical map are regions that are more methylated in the abused than the non-abused group; lower tracks identify probes with the most statistically significant differences). Primers for each PCR are given in Additional file 3: Table S1. They were selected so that the forward primer (denote by ' $F$ ') binds to the left and the reverse primer (denoted by ' $R$ ') binds to the right of the most significantly different probe. In some cases, two sets of PCR primers were designed, denoted by 'set1' and 'set2'. $85 \%$ of the eleven gene promoters show statistically significant $P C R$ quantification differences ${ }^{*}: \mathrm{P}<0.05$; $\left.{ }^{* *}: \mathrm{P}<0.01\right)$, hence validating differences found by microarray.

\section{Additional file 3: Supplementary Material.}

Additional file 4: Figure S3. Promoter methylation associated with childhood abuse. Heatmap showing MeDIP probe values from the 34 differentially methylated promoters (rows) across all 40 participants (columns) based on more stringent thresholds ( $q<0.05$ and $p<0.01$, see Methods). Each promoter is represented by the probe most associated with childhood abuse. Blackened squares above the columns denote non-abuse males, white squares denote those with childhood abuse. Other covariates included are childhood and adulthood socioeconomic position (white $=$ low, gray $=$ high). None appears to explain the main sample clusters.
Additional file 5: Figure S4. Summary of functional analysis. Genes with hypermethylated or hypomethylated promoters in the abuse group were analysed by Ingenuity Pathway Analysis ${ }^{\circ}$. Gene categories enriched with this set of genes as well as enrichment p-values are listed.

Additional file 6: Figure S5. CpG frequency in differentially methylated regions. Bars indicate average normalized CpG frequencies (observed/ expected CpG frequency) of 'all' genomic regions profiled, regions 'hypermethylated' in abused individuals and regions 'hypomethylated' in abused individuals. Error bars depict standard deviation. The dashed line indicates the usual CpG frequency used to identify CpG islands.

Additional file 7: Figure S6. Methylation dependencies across megabases. Shown are correlations of methylation differences from 500 kilobase regions at various distances apart. The level of clustering was quantified as the level of correlation between the differential methylation statistics within promoters at different distances apart. The solid grey region contains the $95 \% \mathrm{Cl}$, and error bars contain the $95 \% \mathrm{Cl}$ for correlation values.

\section{Competing interests}

The authors declare that they have no competing interests.

\section{Authors' contributions}

Study was designed by $\mathrm{CP}, \mathrm{CH}$ and MS. Participants were selected by CP and $\mathrm{CH}$. Methylation analysis was completed by NB and JP. Bioinformatic analysis was performed by MS. The entire process was overseen by MS. JP, NB, CH, MP, SPP, CP, MS and MS all contributed to writing the manuscript. All authors read and approved the final manuscript.

\section{Acknowledgements}

We dedicate this work to the memory of our recently deceased co-author Clyde Hertzman, who played a central role in conceiving of this study and inspiring its completion. Grants from the Canadian Institute of Health Research; MOP-42411 the Sackler program in Psychobiology and Epigenetics at McGill University (to M.S.); fellowship from the Canadian Institute of Health Research and the Fragile X Research Foundation of Canada (to N. B.); the UK Medical Research Council (MRC) (grant G0000934 to the clinical examination and DNA banking of the 1958 cohort); and funding received for the MRC Centre of Epidemiology for Child Health (Grant G0400546) (for SPP). Work undertaken at Great Ormond Street Hospital/University College London, Institute of Child Health is in part supported by funding from the Department of Health's National Institute of Health Research ('Biomedical Research Centres' funding). Laboratory work in the Department of Social Medicine, University of Bristol was supported in part by a grant to MP from the Welcome Trust.

\section{Author details}

${ }^{1}$ Sackler Program for Epigenetics \& Developmental Psychobiology, McGill University, 3655 Promenade Sir William Osler, Montreal H3G 1Y6 QC, Canada. ${ }^{2}$ Department of Pharmacology and Therapeutics, McGill University, 3655 Promenade Sir William Osler, Montreal H3G 1Y6 QC, Canada. ${ }^{3}$ McGill Centre for Bioinformatics, McGill University, 3649 Promenade Sir William Osler, Montreal H3G OB1 QC, Canada. ${ }^{4}$ MRC Centre of Epidemiology for Child Health/ Centre for Paediatric Epidemiology and Biostatistics, UCL Institute of Child Health, 30 Guilford Street, London WC1N 1EH, UK. ${ }^{5}$ Clinical and Molecular Genetics Unit, UCL Institute of Child Health, 30 Guilford Street, London WC1N 1EH, UK. ${ }^{6}$ Human Early Learning Partnership, University of British Columbia, Suite 440, 2206 East Mall, Vancouver V6T 1 Z3 BC, Canada.

Received: 7 August 2013 Accepted: 18 February 2014 Published: 11 March 2014

\section{References}

1. Gilbert R, Widom CS, Browne K, Fergusson D, Webb E, Janson S: Burden and consequences of child maltreatment in high-income countries. Lancet 2009, 373(9657):68-81.

2. Anda RF, Croft JB, Felitti VJ, Nordenberg D, Giles WH, Williamson DF, Giovino GA: Adverse childhood experiences and smoking during adolescence and adulthood. JAMA 1999, 282(17):1652-1658. 
3. Anda RF, Whitfield CL, Felitti VJ, Chapman D, Edwards VJ, Dube SR, Williamson DF: Adverse childhood experiences, alcoholic parents, and later risk of alcoholism and depression. Psychiatr Serv 2002, 53(8):1001-1009.

4. Dube SR, Miller JW, Brown DW, Giles WH, Felitti VJ, Dong M, Anda RF: Adverse childhood experiences and the association with ever using alcohol and initiating alcohol use during adolescence. J Adolesc Health 2006, 38(4):444. e441-410.

5. Felitti VJ, Anda RF, Nordenberg D, Williamson DF, Spitz AM, Edwards V, Koss MP Marks JS: Relationship of childhood abuse and household dysfunction to many of the leading causes of death in adults. The Adverse Childhood Experiences (ACE) study. Am J Prev Med 1998, 14(4):245-258.

6. Dong M, Giles WH, Felitti VJ, Dube SR, Williams JE, Chapman DP, Anda RF: Insights into causal pathways for ischemic heart disease: adverse childhood experiences study. Circulation 2004, 110(13):1761-1766.

7. Lehman BJ, Taylor SE, Kiefe Cl, Seeman TE: Relation of childhood socioeconomic status and family environment to adult metabolic functioning in the CARDIA study. Psychosom Med 2005, 67(6):846-854.

8. Sumanen M, Koskenvuo M, Sillanmaki L, Mattila K: Childhood adversities experienced by working-aged coronary heart disease patients. J Psychosom Res 2005, 59(5):331-335.

9. Wise LA, Palmer JR, Rothman EF, Rosenberg L: Childhood abuse and early menarche: findings from the black women's health study. Am J Publ Health 2009, 99(Suppl 2):S460-S466.

10. Zabin LS, Emerson MR, Rowland DL: Childhood sexual abuse and early menarche: the direction of their relationship and its implications. J Adolesc Health 2005, 36(5):393-400.

11. Vigil JM, Geary DC, Byrd-Craven J: A life history assessment of early childhood sexual abuse in women. Dev Psychol 2005, 41(3):553-561.

12. Fuller-Thomson E, Brennenstuhl S, Frank J: The association between childhood physical abuse and heart disease in adulthood: findings from a representative community sample. Child Abuse Negl 2010, 34(9):689-698.

13. Goodwin RD, Stein MB: Association between childhood trauma and physical disorders among adults in the United States. Psychol Med 2004, 34(3):509-520

14. Springer KW: Childhood physical abuse and midlife physical health: testing a multi-pathway life course model. Soc Sci Med 2009, 69(1):138-146.

15. Jaenisch R, Bird A: Epigenetic regulation of gene expression: how the genome integrates intrinsic and environmental signals. Nat Genet 2003, 33(Suppl):245-254.

16. Chuang JC, Jones PA: Epigenetics and microRNAs. Pediatr Res 2007, 61(5 Pt 2):24R-29R

17. Baer C, Claus R, Frenzel LP, Zucknick M, Park YJ, Gu L, Weichenhan D, Fischer M, Pallasch CP, Herpel E, Rehli M, Byrd JC, Wendtner CM, Plass C: Extensive promoter DNA hypermethylation and hypomethylation is associated with aberrant microRNA expression in chronic lymphocytic leukemia. Canc Res 2012, 72(15):3775-3785.

18. Tobi EW, Slagboom PE, van Dongen J, Kremer D, Stein AD, Putter H, Heijmans BT, Lumey LH: Prenatal famine and genetic variation are independently and additively associated with DNA methylation at regulatory loci within IGF2/H19. PloS One 2012, 7(5):e37933.

19. McGowan PO, Sasaki A, D'Alessio AC, Dymov S, Labonte B, Szyf M, Turecki G, Meaney MJ: Epigenetic regulation of the glucocorticoid receptor in human brain associates with childhood abuse. Nat Neurosci 2009, 12(3):342-348.

20. Roth TL, Lubin FD, Funk AJ, Sweatt JD: Lasting epigenetic influence of early-life adversity on the BDNF gene. Biol Psychiatr 2009, 65(9):760-769.

21. Weaver IC, Cervoni N, Champagne FA, D'Alessio AC, Sharma S, Seckl JR, Dymov S, Szyf M, Meaney MJ: Epigenetic programming by maternal behavior. Nat Neurosci 2004, 7(8):847-854.

22. Razin A, Szyf M: DNA methylation patterns. Formation and function. Biochim Biophys Acta 1984, 782(4):331-342.

23. Szyf M: How do environments talk to genes? Nat Neurosci 2013, 16(1):2-4

24. Borghol N, Suderman M, McArdle W, Racine A, Hallett M, Pembrey M, Hertzman C, Power C, Szyf M: Associations with early-life socio-economic position in adult DNA methylation. Int J Epidemiol 2012, 41(1):62-74.

25. Provencal N, Suderman MJ, Guillemin C, Massart R, Ruggiero A, Wang D, Bennett AJ, Pierre PJ, Friedman DP, Cote SM, Hallett M, Tremblay RE, Suomi SJ, Szyf M: The signature of maternal rearing in the methylome in rhesus macaque prefrontal cortex and T cells. J Neurosci Offic J Soc Neurosci 2012, 32(44):15626-15642.
26. Klengel $T$, Mehta $D$, Anacker $C$, Rex-Haffner M, Pruessner JC, Pariante CM, Pace TW, Mercer KB, Mayberg HS, Bradley B, Nemeroff CB, Holsboer F, Heim CM, Ressler KJ, Rein T, Binder EB: Allele-specific FKBP5 DNA demethylation mediates gene-childhood trauma interactions. Nat Neurosci 2013, 16(1):33-41.

27. Mehta D, Klengel T, Conneely KN, Smith AK, Altmann A, Pace TW, Rex-Haffner M, Loeschner A, Gonik M, Mercer KB, Bradley B, Muller-Myhsok B, Ressler KJ, Binder EB: Childhood maltreatment is associated with distinct genomic and epigenetic profiles in posttraumatic stress disorder. Proc Natl Acad Sci U S A 2013, 110(20):8302-8307.

28. Thomas $C$, Hypponen $\mathrm{E}$, Power $\mathrm{C}$ : Obesity and type 2 diabetes risk in midadult life: the role of childhood adversity. Pediatrics 2008, 121(5):e1240-e1249.

29. Power C, Elliott J: Cohort profile: 1958 British birth cohort (National Child Development Study). Int J Epidemiol 2006, 35(1):34-41.

30. Genome-wide association study of 14,000 cases of seven common diseases and 3,000 shared controls. Nature 2007, 447(7145):661-678.

31. Rosenman S, Rodgers B: Childhood adversity in an Australian population. Soc Psychiatry Psychiatr Epidemiol 2004, 39(9):695-702

32. Smyth GK: Limma: linear models for microarray data. In Bioinformatics and Computational Biology Solutions using $R$ and Bioconductor, Volume 1. Edited by Gentleman VC R, Dudoit S, Irizarry R, Huber W. New York: Springer; 2005:397-420.

33. Gentleman RC, Carey VJ, Bates DM, Bolstad B, Dettling M, Dudoit S, Ellis B, Gautier L, Ge Y, Gentry J, Hornik K, Hothorn T, Huber W, lacus S, Irizarry R, Leisch F, Li C, Maechler M, Rossini AJ, Sawitzki G, Smith C, Smyth G, Tierney $L$, Yang JY, Zhang J: Bioconductor: open software development for computational biology and bioinformatics. Genome Biol 2004, 5(10):R80.

34. Soric B: Statistical "discoveries" and effect-size estimation. J Am Stat Assoc 1989, 84(406):608-610.

35. Benjamini $Y$, Hochberg $Y$ : Controlling the false discovery rate - a practical and powerful approach to multiple testing. J Roy Stat Soc B Met 1995, 57 (1):289-300.

36. Ashburner M, Ball CA, Blake JA, Botstein D, Butler H, Cherry JM, Davis AP Dolinski K, Dwight SS, Eppig JT, Harris MA, Hill DP, Issel-Tarver L, Kasarskis A, Lewis S, Matese JC, Richardson JE, Ringwald M, Rubin GM, Sherlock G: Gene ontology: tool for the unification of biology. Nat Genet 2000, 25(1):25-29.

37. Kanehisa M, Goto S: KEGG: kyoto encyclopedia of genes and genomes. Nucleic Acids Res 2000, 28(1):27-30.

38. Subramanian A, Tamayo P, Mootha VK, Mukherjee S, Ebert BL, Gillette MA, Paulovich A, Pomeroy SL, Golub TR, Lander ES, Mesirov JP: Gene set enrichment analysis: a knowledge-based approach for interpreting genome-wide expression profiles. Proc Natl Acad Sci USA 2005, 102(43):15545-15550.

39. Colella S, Shen L, Baggerly KA, Issa JP, Krahe R: Sensitive and quantitative universal Pyrosequencing methylation analysis of $\mathrm{CpG}$ sites. Biotechniques 2003, 35(1):146-150

40. Rakyan VK, Down TA, Thorne NP, Flicek P, Kulesha E, Graf S, Tomazou EM, Backdahl L, Johnson N, Herberth M, Howe KL, Jackson DK, Miretti MM, Fiegler H, Marioni JC, Birney E, Hubbard TJ, Carter NP, Tavare S, Beck S: An integrated resource for genome-wide identification and analysis of human tissue-specific differentially methylated regions (tDMRs). Genome Res 2008, 18(9):1518-1529.

41. Su Al, Wiltshire T, Batalov S, Lapp H, Ching KA, Block D, Zhang J, Soden R, Hayakawa M, Kreiman G, Cooke MP, Walker JR, Hogenesch JB: A gene atlas of the mouse and human protein-encoding transcriptomes. Proc Natl Acad Sci U S A 2004, 101(16):6062-6067.

42. Reinius LE, Acevedo N, Joerink M, Pershagen G, Dahlen SE, Greco D, Soderhall C, Scheynius A, Kere J: Differential DNA methylation in purified human blood cells: implications for cell lineage and studies on disease susceptibility. PloS One 2012, 7(7):e41361.

43. Lewis BP, Burge CB, Bartel DP: Conserved seed pairing, often flanked by adenosines, indicates that thousands of human genes are microRNA targets. Cell 2005, 120(1):15-20.

44. Bird AP: CpG-rich islands and the function of DNA methylation. Nature 1986, 321(6067):209-213.

45. Aissani B, Bernardi G: CpG islands: features and distribution in the genomes of vertebrates. Gene 1991, 106(2):173-183.

46. Nair SS, Coolen MW, Stirzaker C, Song JZ, Statham AL, Strbenac D, Robinson MW, Clark SJ: Comparison of methyl-DNA immunoprecipitation (MeDIP) and methyl-CpG binding domain (MBD) protein capture for genome-wide DNA methylation analysis reveal CpG sequence coverage bias. Epigenetics 2011, 6(1):34-44. 
47. McGowan PO, Suderman M, Sasaki A, Huang TC, Hallett M, Meaney MJ, Szyf M: Broad epigenetic signature of maternal care in the brain of adult rats. Plos One 2011, 6(2):e14739.

48. Clevers $\mathrm{H}$, van de Wetering M: TCF/LEF factor earn their wings. Trends Genet 1997, 13(12):485-489.

49. Oh DY, Olefsky JM: Medicine. Wnt fans the flames in obesity. Science, 329(5990):397-398.

50. Ouchi N, Higuchi A, Ohashi K, Oshima Y, Gokce N, Shibata R, Akasaki Y, Shimono A, Walsh K: Sfrp5 is an anti-inflammatory adipokine that modulates metabolic dysfunction in obesity. Science 2010, 329(5990):454-457.

51. Prestwich TC, Macdougald OA: Wnt/beta-catenin signaling in adipogenesis and metabolism. Curr Opin Cell Biol 2007, 19(6):612-617.

52. Hattersley AT: Prime suspect: the TCF7L2 gene and type 2 diabetes risk. J Clin Invest 2007, 117(8):2077-2079.

53. Cauchi S, Froguel P: TCF7L2 genetic defect and type 2 diabetes. Curr Diab Rep 2008, 8(2):149-155.

54. Jin T: The WNT, signalling pathway and diabetes mellitus. Diabetologia 2008, 51(10):1771-1780.

55. Schinner S: Wnt-signalling and the metabolic syndrome. Horm Metab Res 2009, 41(2):159-163.

56. Pereira CP, Bachli EB, Schoedon G: The wnt pathway: a macrophage effector molecule that triggers inflammation. Curr Atheroscler Rep 2009, 11(3):236-242.

57. Schett G, Zwerina J, David JP: The role of Wnt proteins in arthritis. Nat Clin Pract Rheumatol 2008, 4(9):473-480.

58. Takahashi-Yanaga F, Sasaguri T: The Wnt/beta-catenin signaling pathway as a target in drug discovery. J Pharmacol Sci 2007, 104(4):293-302.

59. Waltzer L, Bienz M: The control of beta-catenin and TCF during embryonic development and cancer. Canc Metastasis Rev 1999, 18(2):231-246.

60. Feinberg AP, Irizarry RA, Fradin D, Aryee MJ, Murakami P, Aspelund T, Eiriksdottir G, Harris TB, Launer L, Gudnason V, Fallin MD: Personalized epigenomic signatures that are stable over time and covary with body mass index. Sci Transl Med 2010, 2(49):49ra67.

61. Irizarry RA, Ladd-Acosta C, Carvalho B, Wu H, Brandenburg SA, Jeddeloh JA Wen B, Feinberg AP: Comprehensive high-throughput arrays for relative methylation (CHARM). Genome Res 2008, 18(5):780-790.

62. Jia J, Pekowska A, Jaeger S, Benoukraf T, Ferrier P, Spicuglia S: Assessing the efficiency and significance of Methylated DNA Immunoprecipitation (MeDIP) assays in using in vitro methylated genomic DNA. BMC Res Notes 2010, 3:240.

63. Jin SG, Kadam S, Pfeifer GP: Examination of the specificity of DNA methylation profiling techniques towards 5-methylcytosine and 5-hydroxymethylcytosine. Nucleic Acids Res 2010, 38(11):e125.

64. Rajendram R, Ferreira JC, Grafodatskaya D, Choufani S, Chiang T, Pu S, Butcher DT, Wodak SJ, Weksberg R: Assessment of methylation level prediction accuracy in methyl-DNA immunoprecipitation and sodium bisulfite based microarray platforms. Epigenetics 2011, 6(4):410-415.

65. Robinson MD, Stirzaker C, Statham AL, Coolen MW, Song JZ, Nair SS, Strbenac D, Speed TP, Clark SJ: Evaluation of affinity-based genome-wide DNA methylation data: effects of $\mathrm{CpG}$ density, amplification bias, and copy number variation. Genome Res 2010, 20(12):1719-1729.

doi:10.1186/1755-8794-7-13

Cite this article as: Suderman et al: Childhood abuse is associated with methylation of multiple loci in adult DNA. BMC Medical Genomics 2014 7:13.

\section{Submit your next manuscript to BioMed Central and take full advantage of:}

- Convenient online submission

- Thorough peer review

- No space constraints or color figure charges

- Immediate publication on acceptance

- Inclusion in PubMed, CAS, Scopus and Google Scholar

- Research which is freely available for redistribution 